\title{
Methanol Barriers Derived from Layer-by-Layer Assembly of Poly(ethersulfone)s for High Performance Direct Methanol Fuel Cells
}

\author{
Junglim Ok, ${ }^{\dagger,}$ Dong Wook Kim, ${ }^{\dagger}$ Changjin Lee, ${ }^{\dagger}$ Won Choon Choi, ${ }^{\ddagger}$ Sungmin Cho, and Yongku Kang ${ }^{\dagger \cdot}$ \\ ${ }^{\dagger}$ Athanced Materials Division and ${ }^{\dagger}$ New Chemistry Research Dinision, Korea Research Institute of Chemical Technologu \\ Daejeon 305-600, Korea. ${ }^{*}$ E-mail: wangakict re kr \\ ${ }^{8}$ School of Chemical Engineering, Sunghyukw an Lniversitw, Suwon 4+0-746, Korea \\ Received November 15,2007
}

\begin{abstract}
Layer-by'-layer assembled multilayers of poly(ethersulfone)s were deposited on the surface of Nafion membrane for the application of direct methanol fuel cells (DMFC). Aminated poly'(ethersulfone) (APES) and sulfonated poly (ethersulfone) (SPES) were used as a polycation and a polyanion for fabrication of the multilayer films. UV/Vis absorption spectroscopy verified a linear build-up of the multilayers of APES and SPES on the surface of Nafion. Thin multilayer films deposited on the Nafion membrane enabled methanol permeability of the membrane to decrease by $78 \%$ in comparison with the pristine Nafion. The performance of DMFCs in concentrated methanol was highly enlanced by using the multilayer modified Nafion.
\end{abstract}

Key Words : Layer-by-layer self-assembly. Poly(ethersulfone), Nafion membrane. Direct methanol fuel cells. Methanol permeability

\section{Introduction}

Direct methanol fuel cell (DMFC) using a liquid methanol as a fuel is recently recognized as a promising candidate to compete with the conventional batteries for powering portable electronic devices. ${ }^{1-6}$ In the heart of DMFC is the proton exchange membrane. Nafion, which is a fluorocarbon polymer electrolyte with perfluoroether sulfonic acid. serves as a typical membrane for DMFC because it has superior proton conductivity; thermal and chemical durability and oxidative stability: However its high methanol crossover (methanol permeability through the membrane from anode to cathode) not only lowers the fuel efficiency but also decreases the open circuit voltage. resulting in a poor cell performance. ${ }^{7 \delta}$ Several attempts have been carried out to modify the Nafion membrane by blending with other polymers ${ }^{5}$ incorporating inorganic fillers or particles ${ }^{10}$ coating barrier films on the Nafion. ${ }^{13.12}$ and so on. Among them. we are interested in surface modification of Nafion by coating a thin barrier film through a layer-by-layer seif assembly technique.

The layer-by-lay'er assembly is a unique coating method to deposit a thin multilayer film on a substrate by sequential electrostatic adsorption between the negatively and positively charged polyelectrolytes. The simple but highly versatile method allows us to tailor functionality of the films in accordance with our special needs and to control the film thickness in a nanometer regime. Many functional charged species can be applied for this technique. including functional polymers. clay platelets. inorganic nanoparticles. etc. ${ }^{13.14}$ In recent papers. one of the authors (D.W. Kim) reported ordered multilayer nanocomposites by the layer-bylayer self-assembly between delaminated clay nanoparticles and amphiphilic ionic polyacetylenes. ${ }^{15.16}$ The resulting ultrathin films deposited on Nafion membrane was found to block transport of the water vapor through the membrane. ${ }^{\text {li }}$ In our recent experimental results. the multilayer films on the Nafion membranes were also found to be an efficient methanol barrier."' Methanol permeability was reduced to about half by the method.

In this work. we used poly(ethersulfone)s as a barrier to methanol transport because the polymer is known an efficient methanol barrier due to a rigid nature of the polymer backbone and also it exhibits good mechanical. thermal and chemical stabilities. ${ }^{17.18}$ We modified the poly(ethersulfone) by amination and sulfonation reaction in order to increase their proton conductivity and to impart charge nature for layer-by-layer deposition procedure. Then we coated a thin multilayer film on the Nafion using the aminated poly(ethersulfone) and the sulfonated poly'(ethersulfone) by layer-by-layer method. Methanol permeability and proton conductivity of the modified Nafion membranes were measured and performance of DMFC based on the membrane was also investigated.

\section{Experimental}

Poly(ethersulfone) (Udel ${ }^{\sqrt{\beta}}$ P-3500. Amoco) was aminated by azidation of the lithiated poly'(ethersulfone) and then consecutive reduction by $\mathrm{NaBH}_{4} .{ }^{17}$ Sulfonated poly (ethersulfone) (SPES) was prepared by reacting chlorotrimethylsilane and chlorosulfonic acid with poly (ethersulfone) (see Scheme 1). ${ }^{18}$ Structure and degree of substitution of the functionalized poly (ethersulfone) were carefully characterized by means of NMR spectroscopy. Aminated poly(ethersulfone) (APES) was dissolved in dimethylformamide (DMF) at $2 \mathrm{wt} \%$ and then diluted 10 times with addition of deionized water. which was used for polycation solution in the layer-by-layer assembly. SPES was dissolved in DMF at 5 wt $\%$ and then diluted with deionized water to the 
(a)
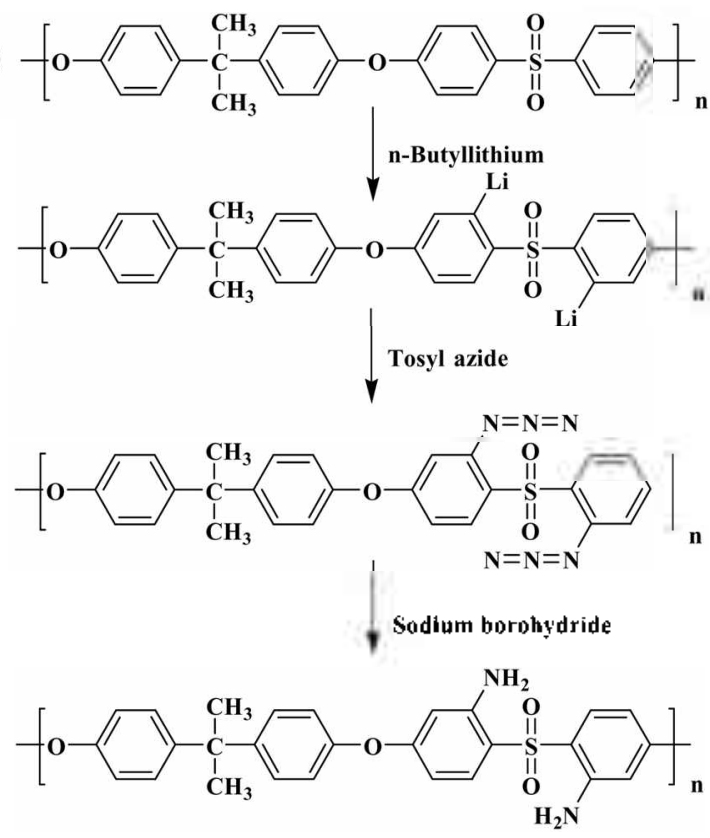

(b)
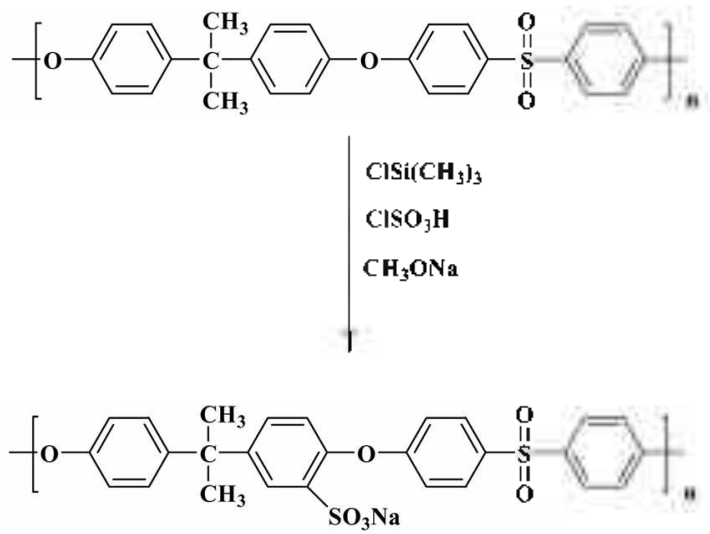

Sulfonated poly(ethersulfone)

(SPES)

\section{Aminated poly(ethersulfone)} (APES)

Scheme 1. Synthetic routes for (a) anninated poly (ethersulfone) (APES) and (b) sulfonated poly(ehtersulfone) (SPES).

concentration of $1 \mathrm{wt} \%$. The SPES solution was used for the polyanion.

Nafion membrane (Nafion ${ }^{\sqrt{3}} 115$ from Aldrich. $127 \mu \mathrm{m}$ thick) was treated by $\mathrm{H}_{2} \mathrm{O}_{2}$ and $\mathrm{H}_{2} \mathrm{SO}_{4}$ solution according to the previously reported procedures. ${ }^{1.9}$ The Nafion mentbrane was dipped in each APES and SPES solutions at room temperature for $10 \mathrm{~min}$ to deposit the multilayer films on the Nafion. After each dipping step. the membrane was rinsed with dejonized water to remove weakly bound polyelectrolyte molecules. The layer-by-layer assembled membrane was finally rinsed with deionized water. followed by protonation in $\mathrm{l} \mathrm{M} \mathrm{H} \mathrm{H}_{2} \mathrm{SO}_{4}$ solution and then rinsed again with deionized water.

The build-up of APES/SPES multilay'ers on Nafion membranes was in-situ monitored by UV/Vis spectroscopy. TEM (model: TECNAI G ${ }^{2}$. Phillips) equipped with Energy Dispersive X-ray Spectroscopy (EDXS) was used to examine the thickness and morphology of the multilayers.

Proton conductivity of the modified Nafion was measured in deionized water at room temperature using a four-probe conductivity cell equipped with impedance analyzer (4194A. Hewlett-Packard Co.).

Methanol permeability of the membrane was determined by RI-detector at $30^{\circ} \mathrm{C}$ using a diffusion cell consisting of two compartments that were separated by the membrane. One compartment of the cell had a $2 \mathrm{M}$ methanol solution in deionized water and the other compartment was filled with only deionized water. Solution in both cell compartments was stirred during the experiment. ${ }^{\text {? }}$

To test perfomance of DMFCs, Pt-Ru (atomic ratio $=1: 1$ ) and Pt black cataly st (Jolnnson Mattey Co.) with a loading of
$5 \mathrm{mg} / \mathrm{cm}^{2}$ were used in each electrode. Catalyst ink, which was a mixture of the catalyst powder. Nafion solution (Aldrich. $5 \mathrm{wt} \%$ solution in lower aliphatic alcohols/water mixture). isopropyl alcohol, and water, was coated onto the polyimide films. The catalyzed layers were then transferred onto the Nafion membrane by the decal method. ${ }^{21}$ The catalyzed membrane was hot-pressed at $130^{\circ} \mathrm{C}$ under a pressure of $6 \mathrm{MPa}$ for $5 \mathrm{~min}$. The geometrical area of the electrode was $4 \mathrm{~cm}^{2}$. The methanol solution $(1,5.8 \mathrm{M})$ was fed to the anode side at $2 \mathrm{~mL} / \mathrm{min}$ and the pure oxygen was supplied to the cathode at $500 \mathrm{~mL} / \mathrm{min}$.

\section{Results and Discussion}

Synthetic routes for the aminated poly(ethersulfone) and the sulfonated poly (ethersulfone) are described in Scheme 1. Poly(ethersulfone) was effectively aminated by successive reactions of lithiation of the ortho position to sulfonyl group in the polymer backbone. azidation with tosyl azide. and reduction by sodium borohydride. Degree of substitution (DS: the number of functional group in the repeating unit) in the aminated poly(ethersulfone) was estimated by comparing integral of the amine peak at $6.06 \mathrm{ppm}$ with one of the aromatic protons peaks at 6.18-7.71 ppm in the ${ }^{1} \mathrm{H}$ NMR spectrum according to the literature. ${ }^{17}$ The DS was found to be 1.93. Sulfonation of the poly (ethersulfone) was performed by chlorotrimethylsilane and chlorosulfonic acid. Its DS was estimated 0.50 by comparing integral ratios of the aromatic protons at $6.93-7.82 \mathrm{ppm}$ in ${ }^{1} \mathrm{H}$ NMR spectrum according to the literature ${ }^{\text {? }}$

APES and SPES solutions in the mixture of DMF and 


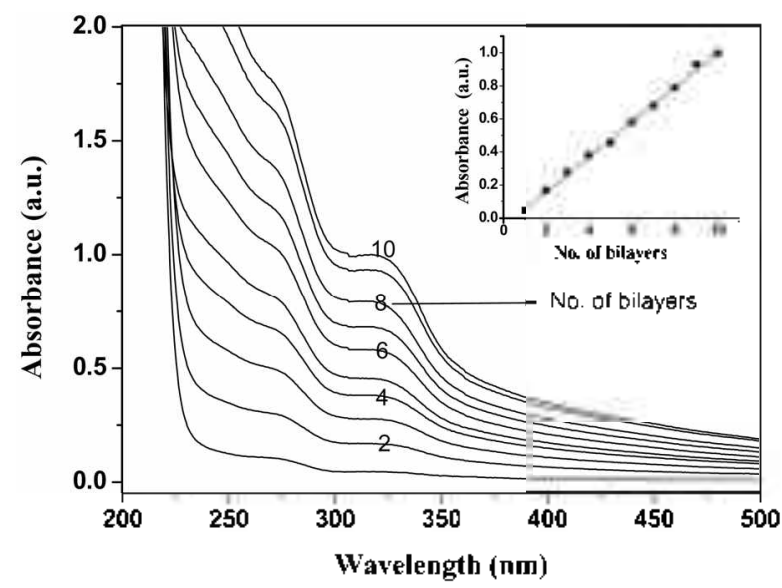

Figure 1. The UV/Vis absonption spectra of the Nation membrane deposited with multilayers of APES and SPES by layer-by-layer assembly. The inset depicts the change of the absorbance at $325 \mathrm{~nm}$ as a function of the number of bilavers.

water were used to prepare the multilayer films on the Nafion membrane by layer-by-layer self-assembly technique. The sequential build-up of the oppositely charged polymers on the nembrane was in-situ monitored by UV/ Vis absorption spectroscopy as shown in Figure 1. The absorption spectra showed linear increase of the optical density at $325 \mathrm{~nm}$. which was characteristic absorption band for APES. This indicated that the same amount of the polymers was deposited in every dipping cycle and the multilayers were deposited in a regular manner.

TEM equipped with EDXS was used to visually investigate the morphology and thickness of the 10 bilayers of APES and SPES on the surface of Nafion membrane. Figure 2(a) showed a cross-sectional intage of the modified Nafion membrane embedded in epoxy resin, which was microtomed in a cryogenic environment. Figure 2(b) described EDXS line scan result. in which concentration profiles of fluorine and sulfur atoms between the points A and B in Figure 2(a) were displayed. The fluorine content abnuptly increased as the EDXS line scan approached the point $B$. indicating that the point $\mathrm{A}$ belonged to the epoxy region and $\mathrm{B}$ to the Nafion. The dark narrow band between $A$ and $B$ must be the multilay'ers of APES and SPES containing lots of sulfur atoms since the concentration of sulfur was shown much higher over the region. TEM image in Figure 2(a) revealed that the 10 bilayers were approximately $300 \mathrm{~mm}$ thick, which corresponded to $30 \mathrm{~nm}$ per bilayer. Also the image indicated that the multilayers were deposited uniformly over the entire surface of the Nafion membrane.

Table 1 summarized the methanol permeability and ionic conductivity of the multilay'er-deposited Nafion membranes together with those of the pristine membrane. Methanol permeability was reduced to $1.24 \times 10^{-6} \mathrm{~cm}^{2} / \mathrm{s}$ for the 5 bilayer-deposited membrane and $3.81 \times 10^{-7} \mathrm{~cm}^{2} / \mathrm{s}$ for the 10-bilayer-deposited membrane. The multilayers of the poly(ethersulfone)s take up only $0.2 \%$ or so of the total mass of membranes considering the thicknesses of the multilayers and the Nafion membrane (300 $\mathrm{nm}$ vs. $127 \mu \mathrm{mm}$ ). Our results (a)

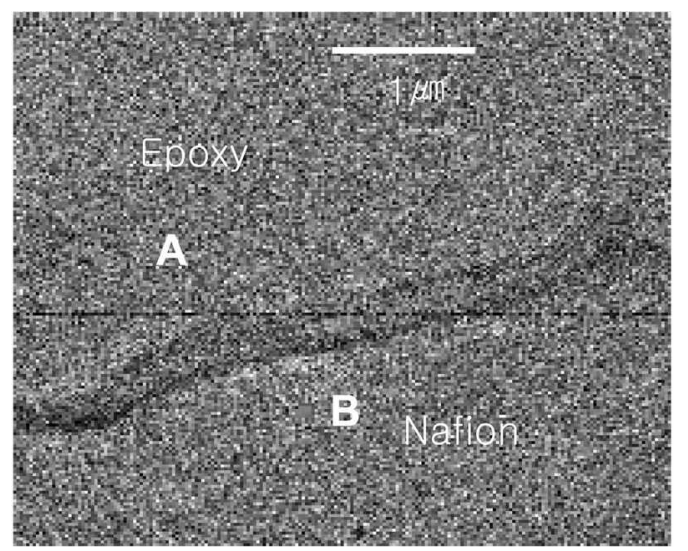

(b)

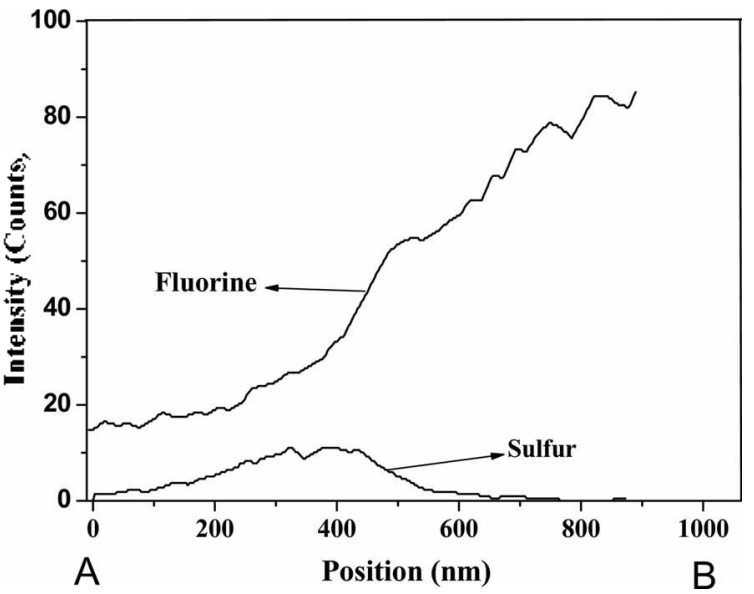

Figure 2. (a) TEM image of cross-section obtained by cryogenic microtoming the Nafion membrane deposited with 10 bilayers of APES and SPES, which was embedded in epony resin, and (b) The change of intensity of fluorine and sulfur content from eposy region to Nation obtained by ELXS line scan experiment.

Table 1. Methanol permeability and ionic conductivity of the pristine Nafion and the multilayer-deposited Nafion membranes

\begin{tabular}{lcc}
\hline \multicolumn{1}{c}{ Samples } & $\begin{array}{c}\text { Methanol } \\
\text { permeability } \\
\left(\mathrm{cm}^{2} / \mathrm{s}\right)\end{array}$ & $\begin{array}{c}\text { Ionic } \\
\text { Conductivity } \\
\left(\mathrm{S} / \mathrm{cm}^{2}\right)\end{array}$ \\
\hline Pristine Nation & $1.74 \times 10^{-5}$ & $8.81 \times 10^{-2}$ \\
5 bilayer-deposited Nafion & $1.24 \times 10^{-5}$ & $6.4 \times 10^{-2}$ \\
10 bilayer-deposited Nation & $3.81 \times 10^{-3}$ & $6.0 \times 10^{-2}$ \\
\hline
\end{tabular}

indicated that such thin multilayers were an effective methanol barrier. The methanol permeability was dropped by $78 \%$ when it was compared to the pristine Nafion. Ion conductivity. however. was affected adversely by the multilayer deposition. The 10 bilayer-deposited membrane showed a $32 \%$ decrease in ionic conductivity than the pristine one. Being compared with the $78 \%$ decrease in methanol permeability. $32 \%$ drop in ionic conductivity was not much Such relatively small decrease in ion conductivity would be because the sulfonated poly(ethersulfone) contained sulfonic acid that may serve as a proton conductor.

DMFC was prepared using the 10 bilayer-deposited Nafion membranes and its perfomance was compared with 
Table 2. Open circuit voltage and maxinum power density of the direct methanol fuel cells using the pristine Nafion and the 10 bilayerdeposited Nafion membranes at the feeding concentration of methanol of 1,5 , and $8 \mathrm{M}$ and at the operating temperature of 30 and $60^{\circ} \mathrm{C}$

\begin{tabular}{|c|c|c|c|c|c|c|c|}
\hline \multicolumn{2}{|c|}{ Feeding concentration of methanol } & \multicolumn{2}{|c|}{$1 \mathrm{M}$} & \multicolumn{2}{|c|}{$5 \mathrm{M}$} & \multicolumn{2}{|c|}{$8 \mathrm{M}$} \\
\hline \multicolumn{2}{|c|}{ Operating temperature } & $30^{\circ} \mathrm{C}$ & $60^{\circ} \mathrm{C}$ & $30^{\circ} \mathrm{C}$ & $60^{\circ} \mathrm{C}$ & $30^{\circ} \mathrm{C}$ & $60^{\circ} \mathrm{C}$ \\
\hline \multirow{2}{*}{$\begin{array}{l}\text { Open circuit voltage } \\
(\mathrm{mV})\end{array}$} & Pristine Nation & 610 & 672 & 480 & 530 & 415 & 485 \\
\hline & 10 bilayer-deposited Nation & 651 & 708 & 580 & 614 & 549 & 551 \\
\hline \multirow{2}{*}{$\begin{array}{l}\text { Maximum power density } \\
\left(\mathrm{mW} / \mathrm{cm}^{2}\right)\end{array}$} & Pristine Nation & 32.45 & 89.5 & 10.43 & 31.05 & 7.65 & 18.59 \\
\hline & 10 bilayer-deposited Nafion & 44.55 & 92.88 & 29.64 & 58.9 & 18.9 & 39.65 \\
\hline
\end{tabular}
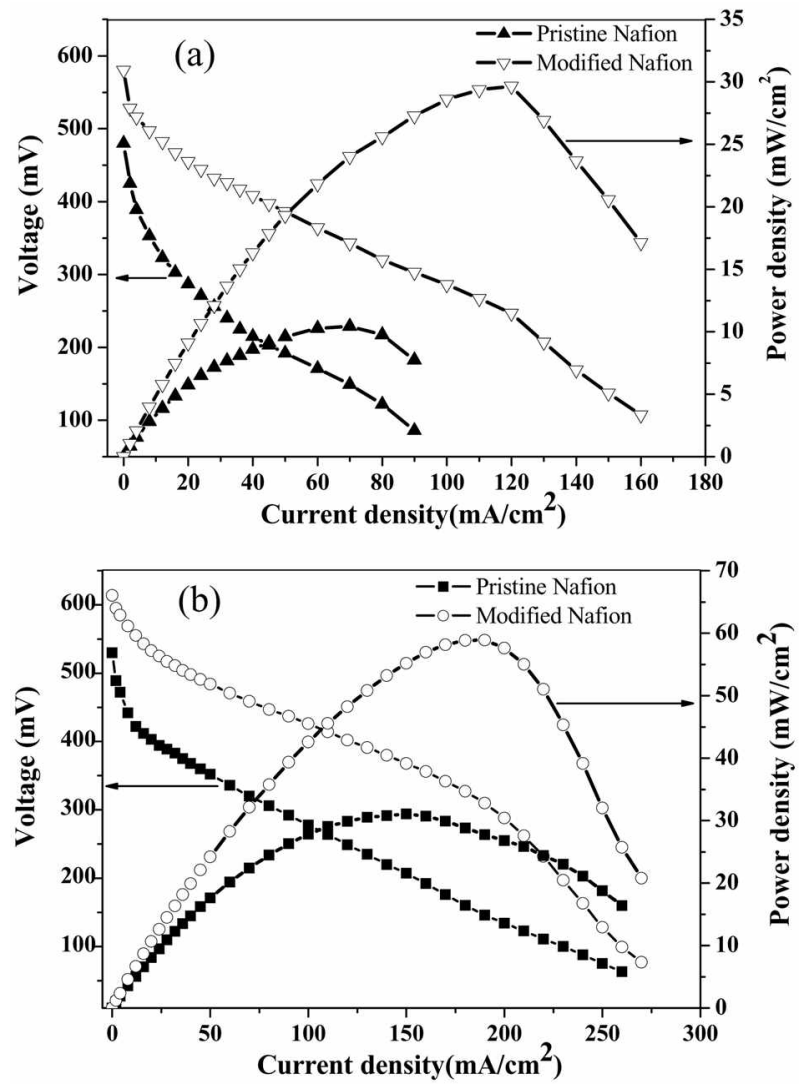

Figure 3. The polarization curves of direct methanol fuel cells using the pristine Nafion and the 10 bilayer-deposited Nafion membranes (a) at $30^{\circ} \mathrm{C}$ and (b) at $60^{\circ} \mathrm{C}$ at the feeding concentration of methanol of $5 \mathrm{M}$.

one based on the pristine Nafion. Figure 3 showed the single cell perfornances of DMFCs prepared by the modified Nafion membrane and the pristine one by feeding $5 \mathrm{M}$ methanol at $30^{\circ} \mathrm{C}$ and $60^{\circ} \mathrm{C}$. The open circuit voltage was measured $480 \mathrm{mV}$ at $30^{\circ} \mathrm{C}$ and $530 \mathrm{mV}$ at $60^{\circ} \mathrm{C}$ for the cell using the pristine Nafion. With the Nafion mentbrane deposited by the 10 bilayers of poly(ethersulfone)s. the open circuit voltage increased to $580 \mathrm{mV}$ at $30^{\circ} \mathrm{C}$ and to $614 \mathrm{mV}$ at $60^{\circ} \mathrm{C}$. The decrease in methanol crossover by the APES/ SPES multilayers seemed to result in the higher open circuit voltage than the pristine Nafion by $21 \%$ at $30{ }^{\circ} \mathrm{C}$ and $16 \%$ at $60^{\circ} \mathrm{C}$. The maximum power density of the cells was much greatly affected by the modification of the membrane. The maximum power density jumped 2.8 times at $30^{\circ} \mathrm{C}$ and 1.9 times at $60^{\circ} \mathrm{C}$ compared to the pristine Nafion.
The cell performance was also measured at several different feeding concentrations of methanol as summarized in Table 2. In case of the pristine Nafion. the cell performance declines drastically as the methanol solution concentrates from $\mathrm{l} \mathrm{M}$ to $8 \mathrm{M}$. This was because the methanol crossover in the pristine Nafion became severer at a higher methanol concentration and hence the performance of DMFC deteriorated. With the modified Nafion membrane. the cell performance became much better at higher methanol concentration. At $8 \mathrm{M}$. for example. the open circuit voltage of the cell based on the modified Nafion increased by $134 \mathrm{mV}$ at $30^{\circ} \mathrm{C}$ and $66 \mathrm{mV}$ at $60^{\circ} \mathrm{C}$. and the maximum power density increased by 2.5 times at $30^{\circ} \mathrm{C}$ and 2.1 times at 60 ${ }^{\circ} \mathrm{C}$ in comparison with the cell of the pristine Nafion. This result again showed that the APES/SPES multilayers were effectively deterring the methanol transport through the membranes and enhancing the cell performance.

In conclusion. we have demonstrated here that modification of Nafion membrane through layer-by-layer assembly of poly(ethersulfone)s has led to 2.8 times increase in maximum power density in DMFCs. The self-assembled multilayer was found to effectively prevent the methanol from migrating through the membrane by $78 \%$. It is worthy of note that the layer-by-layer assembly method is a very simple procedure and the resulting films are as thin as 300 $\mathrm{nm}$. but the effect is found to be substantial in tenns of the cell performance.

\section{References}

1. Kordesch. K.: Smader. G. Fuel Cell and Their Applications: WILEY-VCH: Weinheim. 1996.

2. Bockris. T. O'M: Srinivasan. S. Fuel Cells: Their Electochentismy. MoGraw-Hill Book Company: New York. 1969.

3. DeLuea. N. W. Elabd, Y. A. J. Polm. Sci.: Part B: Polym Plys. 2006. H, 2201

4. Han1. S. K.: Hwang. T. K.: Han1. O. H. Bull. Korean Chent. Soc. 2007. 28. 2442.

5. Liu. I. G: Zhou. Z. H.: Zhao. X. S.: Xitr. Q.: Sun. G. Q.: Yi. B. L. Phys. Chem. Chem. Phys. 2004. 6, 134.

6. Ye. Q; Zhao. T. S.; Liu. J. G. Electrochem. Solid-State Lett 2005. 8. A549.

7. Kim. Y. T.: Choi. W. C.: Woo. S. I.: Hong. W. H. Electrochin. deta $2004 .+9.3227$.

8. Mauritz. K.: Moore. R. Chem. Rev: 2004. 104. 4535

9. DeLuca, N. W.: Elabd, Y. A. J. Hembr: Sci. 2006, 282. 217.

10. (a) Libby. B.: Smyrl, W. H.; Cussler. E. L. Electrochem. Solid State Lett. 2001. 4. A197. (b) Miyake. N.; Wainright, J. S.; Savinell. R. F. J. Electrochent Soc. 2001. 148. A905. 
11. (a) Hobson. L. J.: Ozu. H.: Yamaguchi. M.: Hayase. S. J. Electrochem. Soc. 2001. I 18. Al185. (b) Jiang. S.: Liu. Z.: Tian. Z. Q. Adt: A fater 2006. 18. 1068. (c) Tang. H.: Pan. M.: Jiang. S.: Wan. Z.: Ylan. R. Colloids Surf. A: Phnsicochem. Eng. Aspects $2005,262,65$.

12. Kim, D. W: Choi. H. S: Lee. C: Blunstein. A; Kang. Y. Electrochim. Acta 2004. 50.659

13. (a) Decher. G. Science 1997. 277, 1232. (b) Decher. G.: Eckle. M.: Schmitt. J.: Struth. B. Cument Opin. Colloid Interface Sa. 1998. 3. 32. (c) Decher. G.: Schlenoff. J. B. Multhlaver Thin Fihns: WILEY-VCH: Weinheim. 2003.

14. (a) Hong, J. D.; Park, E. S.: Park. A. L. Bull Korean Chem. Soc. 1998. 19. 1156. (b) Kumar. S. K.: Park. J. K.: Hong. J. D. Langmil 2007. 23. 5093 .

15. (a) Kim. D. W.: Blumstein. A.: Kumar. J.: Samuelson. L. A.:
Kang. B.: Sung. C. Chem. Hater. 2002. 14. 3925. (b) Kinn. D. W. Kumar. J.: Blumstein. A. Appl. Clav Sci. 2005. 30. 134.

16. Kiml. D. W.: Ku. B. C.: Steeves. D:: Nagarajan. R.: Blumstein. A.: Kumar. J.: Gibson. P. W.: Ratto, J. A.: Samuelson. L. A. J. Memb: Sci. 2006, 275, 12.

17. (a) Guiver, M. D.; Robertson, G. P. Macromolecules 1995. 28.94 (b) Guiver. M. D.: Robertson. G. P.: Foley. S. Hacronolecules 1995. 28. 7612 .

18. Nolte. R.: Ledjeff. K.: Bauer. M.: Mulhaupt. R. J. Membr: Sci. 1993. 83,211

19. Lewis, F. A. Iht. J. Hydrogen Energ, 1996. 21, 461.

20. Tricoli. V. J. Electrochem. Soc. 1998. 145. 3798.

21. Wilson. M. S.: Gottesfeld. S. J. Appl. Electrochem. 1992. 22. 1.

22. Noshay. A.: Robeson. L. M. J. Appl. Polmm Sci. 1976. 20. 1885. 